\title{
Diving exposure and health effects in divers working in different areas of professional diving
}

\author{
Ågot Irgens ${ }^{1}$, Kari Troland ${ }^{2}$, Rune Djurhuus ${ }^{2}$, Marit Grønning ${ }^{1,3}$ \\ ${ }^{1}$ Norwegian Centre for Diving Medicine, Department of Occupational Medicine, Haukeland University Hospital, Bergen, Norway \\ ${ }^{2}$ Department of Occupational Medicine, Haukeland University Hospital, Bergen, Norway \\ ${ }^{3}$ Department of Clinical Medicine (K1), University of Bergen, Norway
}

\begin{abstract}
Background: The aim of the present study was to compare diving exposure and health effects in different areas of professional diving.

Materials and methods: The Norwegian Labour Inspection Authority's Diving Register contains data on all professional inshore divers who have held a diving certificate at any time since 1980. Of these divers, the "Norwegian diver 2011" questionnaire was completed by 2848 (48.7\%). A total of 1167 male divers reported that they often worked in one area of diving only (rescue diving, diving instruction, fish farming, quay/construction work and offshore/oil related). In the analysis of these divers, rescue divers were used as referents as they reported the lowest number of dives.

Results: Age distribution, the proportion of retired divers and the mean number of dives completed varied between the different areas of professional diving. Compared to rescue divers, divers in fish farming, quay/ /construction work and offshore/oil related work more often experienced physically demanding diving. Divers in fish farming more often had no day off after 3 days of physically demanding work compared to rescue divers. All groups except offshore divers reported making further dives after one physically demanding dive on the same day. All groups reported more frequent decompression sickness than did the referents and divers in quay/construction and offshore/oil related diving reported more frequent episodes of unconsciousness during diving than did the referents. Divers in fish farming, in quay/construction work and oil/ /offshore related diving obtained a higher symptom score than the referents and the two latter groups also reported more frequent adverse health effects due to diving than the referents. Health related physical and mental component summary scores were lower in all other groups than in referents.

Conclusions: Compared to the rescue divers, divers in quay/construction work and offshore/oil related divers reported more adverse health effects and obtained a higher symptom score.
\end{abstract}

(Int Marit Health 2016; 67, 4: 235-242)

Key words: professional diver, exposure, health effect

\section{INTRODUCTION}

Apart from the immediate risks associated with the technical and operational procedures including decompression, diving is associated with exposure to hyperoxia, high ambient pressure and increased gas density.

Several of these factors might affect divers' health; a group in which a supreme physical and mental health is required in order to obtain and maintain a valid certificate for occupational diving [1].
Norwegian inshore divers are certified by the Norwegian Labour Inspection Authority, an occupational safety and health agency of the Ministry of Labour. From 1980 onwards, the Labour Inspection Authority has operated the Norwegian Inshore Diver Registry (Diver Registry) that contains data on all divers with a certificate valid for professional diving. The Diver Registry includes inshore divers, while the Petroleum Safety Authority Norway manages a separate registry of offshore divers. Those diving both inshore and off- 
shore are recorded in both registries. By August 2010, 7079 divers were included in the Diver Registry and altogether 5854 of these divers could be identified by their national identification number, providing their home addresses. We have previously used this data in three register based studies on mortality, cancer, and perinatal outcome in the offspring of male divers [2-4].

The diving exposure differs due to various diving techniques and working conditions among professional inshore and offshore divers. Inshore diving includes construction work, fish farming, shellfish harvesting, rescue diving, diving instruction, marine research and photography. Offshore diving in Norway is related to the petroleum industry and includes construction and inspection at depths that require saturation diving.

Much information is lacking on education, exposure and health effects in Norwegian inshore divers. Hence, all divers in the Diver Registry were asked to participate in the "Norwegian diver 2011" questionnaire survey.

\section{MATERIALS AND METHODS}

Based on the "Norwegian diver 2011" questionnaire survey $[5,6]$, we had the opportunity to compare diving exposure and health effects in divers working in different areas of professional diving. The comprehensive questionnaire used in the "Norwegian diver 2011" was prepared and sent by mail to all 5854 identified divers. A stamped return envelope was enclosed $[5,6]$. One reminder was sent.

The divers were asked in which of the below do you work or have you worked as a diver: quay/construction work, fish farming, shellfish harvesting, offshore/oil related, rescue diving, diving photography, diving instruction and marine research. The amount of work in each area of diving was graded as: "often", "seldom" or "never". Data included in this study are shown in Table 1.

The divers included in the study had given their written consent and the study was approved by the Regional committee for medical and health research ethics (REC WEST 2010; 02529).

\section{STATISTICAL METHODS}

For all outcome variables, the different study groups were compared to the rescue divers as a reference as they reported the lowest number of dives. Differences in continuous outcome variables were analysed by Univariate General Linear Modelling. Relative risks were analysed by Generalised Linear Models with binomial distribution and log link. P-values (significance level 0.05) or $95 \%$ confidence intervals $(\mathrm{Cl})$ were reported. All statistical analyses were performed by IBM, SPSS Statistics version 22 [7].

\section{RESULTS}

A total of 2848 divers responded, 2663 male divers (response rate $49 \%$ ) and 385 female divers (response rate 48\%).

The number of divers who reported that they "often" had been employed in the areas of professional diving was: 714 in quay/construction, 362 in fish farming, 103 in shellfish harvesting, 275 in offshore/oil related diving, 483 in rescue diving, 179 in diving photography, 613 in diving instruction and 115 in marine research. To be able to separate the different groups, we excluded divers who had marked "often" for more than one type of professional diving, leaving 1232 divers who often worked in one area only. Five areas were represented.

Only 65 of these were female (5\%), most of whom (75\%) worked as diving instructors, whereas male divers represented several different professional diving areas. Due to these differences, we chose to exclude the female divers, leaving a study population of 1167 male divers who worked in the following areas: $314(27 \%)$ in rescue diving, 374 (32\%) in diving instruction, 112 (10\%) in fish farming, 293 (25\%) in quay/construction work and $74(6 \%)$ in offshore/ /oil related. The distribution of the included study groups are shown in Figure 1.

\section{DIVER CHARACTERISTICS}

The age distribution differed between study groups (Fig. 2A). Nine hundred and ninety-three divers answered the question "have stopped working as professional diver", of which $58 \%$ had actually retired. Sixty four (87.7\%) offshore/ /oil related divers had retired, while fewer rescue divers (45.7\%), diver instructors $(50.7 \%)$, divers in fish farming (61.9\%) and quay/construction divers (66.9\%) had stopped working. Compared to rescue divers, divers in instruction and fish farming were younger and divers in offshore/oil related areas were older (Fig. 2A). Quay/construction divers stopped diving earlier than rescue divers (Fig. 2B). Ordinary diving depth also differed between the groups (Fig. 2C) and compared to rescue divers the mean number of dives completed was higher in all other study groups except offshore divers (Fig. 2D).

\section{EXPOSURE}

The number of divers who reported physically demanding diving differed between the study groups (Table 2). Compared to rescue divers, divers in fish farming, quay/ /construction and offshore/oil related divers had a higher relative risk of physically demanding diving.

The number of divers often having no day off after 3 days of physically demanding diving differed between groups (Table 2). Compared to rescue divers, this was more frequent for divers in fish farming. 
Table 1. Questionnaire - occupational diving and health effects

\begin{tabular}{|c|c|c|c|}
\hline Diver characteristics & \multicolumn{2}{|l|}{ Question details } & Code \\
\hline \multicolumn{4}{|l|}{ Age } \\
\hline Retirement & \multirow{4}{*}{\multicolumn{2}{|c|}{ Have you stopped working as professional diver? }} & Yes/no \\
\hline Year stopped diving & & & \\
\hline Exposure variables & & & \\
\hline $\begin{array}{l}\text { Total number of dives } \\
\text { Ordinary diving depth }\end{array}$ & & & \\
\hline Physically demanding diving & \multicolumn{2}{|c|}{$\begin{array}{l}\text { Have you ever experienced physically demanding diving? The following events could } \\
\text { be ticked off: "often", "sometimes" and "seldom" for the time periods (before } 2005 \text {, } \\
2005-2009, \text { from 2010). A dichotomy variable was constructed: "yes" if at least one } \\
\text { of these periods had been answered "often", otherwise "no". }\end{array}$} & Yes/no \\
\hline $\begin{array}{l}\text { No day off after } 3 \text { days of } \\
\text { physically demanding dives }\end{array}$ & \multicolumn{2}{|c|}{$\begin{array}{l}\text { Have you ever experienced lack of a day off without diving after } 3 \text { days of demanding } \\
\text { diving? The following events could be ticked off: "often", "sometimes" and "seldom" } \\
\text { for the time periods (before 2005, 2005-2009, from 2010). A dichotomy variable } \\
\text { was constructed: "yes" if at least one of these periods had been answered "often", } \\
\text { otherwise "no". }\end{array}$} & Yes/no \\
\hline $\begin{array}{l}\text { Frequently carried on diving } \\
\text { after a physically demanding } \\
\text { dive }\end{array}$ & \multicolumn{2}{|c|}{$\begin{array}{l}\text { Have you ever experienced repeated diving if the first dive was demanding? The follo- } \\
\text { wing events could be ticked off: "often", "sometimes" and "seldom" for the time pe- } \\
\text { riods (before 2005, 2005-2009, from 2010). A dichotomy variable was constructed: } \\
\text { "yes" if at least one of these periods had been answered "often", otherwise "no". }\end{array}$} & Yes/no \\
\hline Life threatening events & \multicolumn{2}{|c|}{$\begin{array}{l}\text { "Yes" if at least one of } 5 \text { events (gas cut, hit or almost hit by falling object, deviation } \\
\text { from vessel, being stuck under water or other life threatening events, other) had been } \\
\text { ticked off, otherwise "no". }\end{array}$} & Yes/no \\
\hline $\begin{array}{l}\text { Psychologically demanding } \\
\text { events }\end{array}$ & \multicolumn{2}{|c|}{$\begin{array}{l}\text { "Yes" if at least one of the } 5 \text { events (psychologically demanding events, search for } \\
\text { drowned person, search for drowned children, loss of colleague or friend, experienced } \\
\text { near miss of colleague, other) had been ticked off, otherwise "no". }\end{array}$} & Yes/no \\
\hline Objective health problems & \multicolumn{2}{|l|}{ Question details } & \\
\hline Decompression sickness & \multicolumn{2}{|l|}{ Have you ever had an incidence of decompression sickness } & Yes/no \\
\hline Unconsciousness & \multicolumn{2}{|l|}{ Have you ever experienced unconsciousness during diving } & Yes/no \\
\hline Subjective health problems & \multicolumn{2}{|l|}{ Question details } & \\
\hline Adverse health effects & \multicolumn{2}{|l|}{$\begin{array}{l}\text { Do you think diving has affected your health? "no effect", "positive effect" } \\
\text { or "negative effect". }\end{array}$} & Yes/no \\
\hline \multicolumn{2}{|l|}{ Symptoms } & No. & Score \\
\hline Lung & Cough and breathlessness & 7 & Pos. response/7 \\
\hline Hand or arm & $\begin{array}{l}\text { Tingling, pricking, numbness in hand, white fingers, pain and sensation, } \\
\text { stiffness in hand or arm, disabled due to symptoms }\end{array}$ & 8 & Pos. response/8 \\
\hline Musculoskeletal & $\begin{array}{l}\text { Pain or stiffness in neck, upper part of back, lumbar region, shoulder, } \\
\text { elbow, wrist/hand, groin, hip, knee, ankle/foot }\end{array}$ & 10 & $\begin{array}{l}\text { Pos. respon- } \\
\text { se/10 }\end{array}$ \\
\hline Ear, nose, throat & $\begin{array}{l}\text { Pain or packed sinus, tinnitus, reduces hearing, external ear } \\
\text { eczema/complaints }\end{array}$ & 4 & Pos. response/4 \\
\hline Gastrointestinal & Heartburn, sour belch, stomach ache, diarrhoea, obstipation & 4 & Pos. response/4 \\
\hline Mental distress & $\begin{array}{l}\text { Attention or concentration problems, irritability, forgetfulness, anxiety, } \\
\text { depression, difficulties getting organized }\end{array}$ & 6 & Pos. response/ 6 \\
\hline Sleep & $\begin{array}{l}\text { Sleep problem during day, evening, night, waking up, could not fell } \\
\text { asleep, nightmare, increased need of sleep, not refreshed after sleep }\end{array}$ & 7 & Pos. response/7 \\
\hline Sum symptom score & $\begin{array}{l}\text { Symptom score was calculated as number of positive response per } \\
\text { total number of symptoms. }\end{array}$ & & $\Sigma$ scores \\
\hline $\begin{array}{l}\text { Short-Form 12-Item Health } \\
\text { Survey (SF-12) }\end{array}$ & The two summary measures, physical score and mental score. & & \\
\hline
\end{tabular}




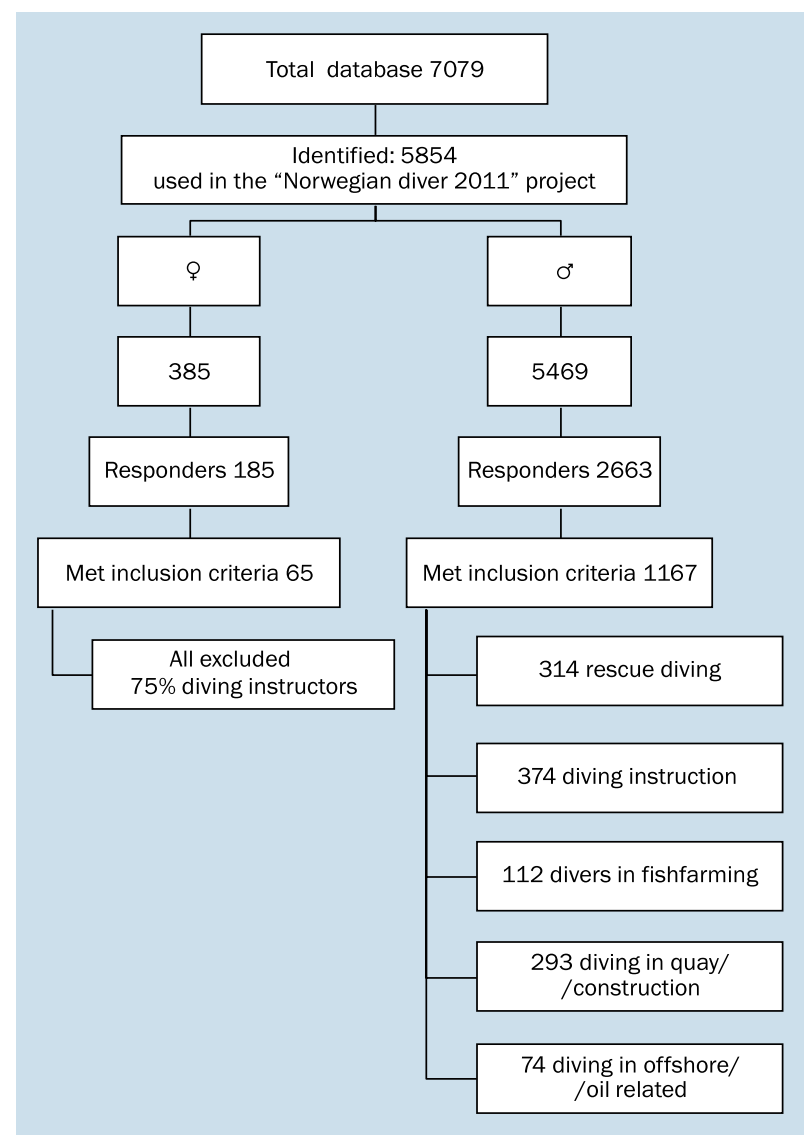

Figure 1. Distribution of different groups of professional divers. Data from the Norwegian Inshore Diver database was used in "Norwegian diver 2011" project

The number of divers who reported making further dives the same day after one physically demanding dive also differed between groups (Table 2). Compared to rescue divers, this was more frequent amongst all groups except offshore divers.

Seventy three per cent of the divers responded to the question of experiencing at least one life threatening event. The number of divers who had experienced at least one life threatening event differed between the groups (Table 2), but compared to rescue divers, no statistically significant differences were seen.

Seventy three per cent of the divers responded to the question of experiencing of all divers who responded at least one psychologically demanding event. Compared to the referent, all except offshore/oil divers, reported significantly less events (Table 2).

\section{OBJECTIVE HEALTH EFFECTS}

A total of 1144 (98\%) responded to the question "Have you ever had decompression sickness". Of these, 190 (16.6\%) had experienced decompression sickness (DCS). The number of divers having experienced DCS differed between study groups (Table 3) - compared to rescue divers, all other groups had a higher relative risk of DCS.
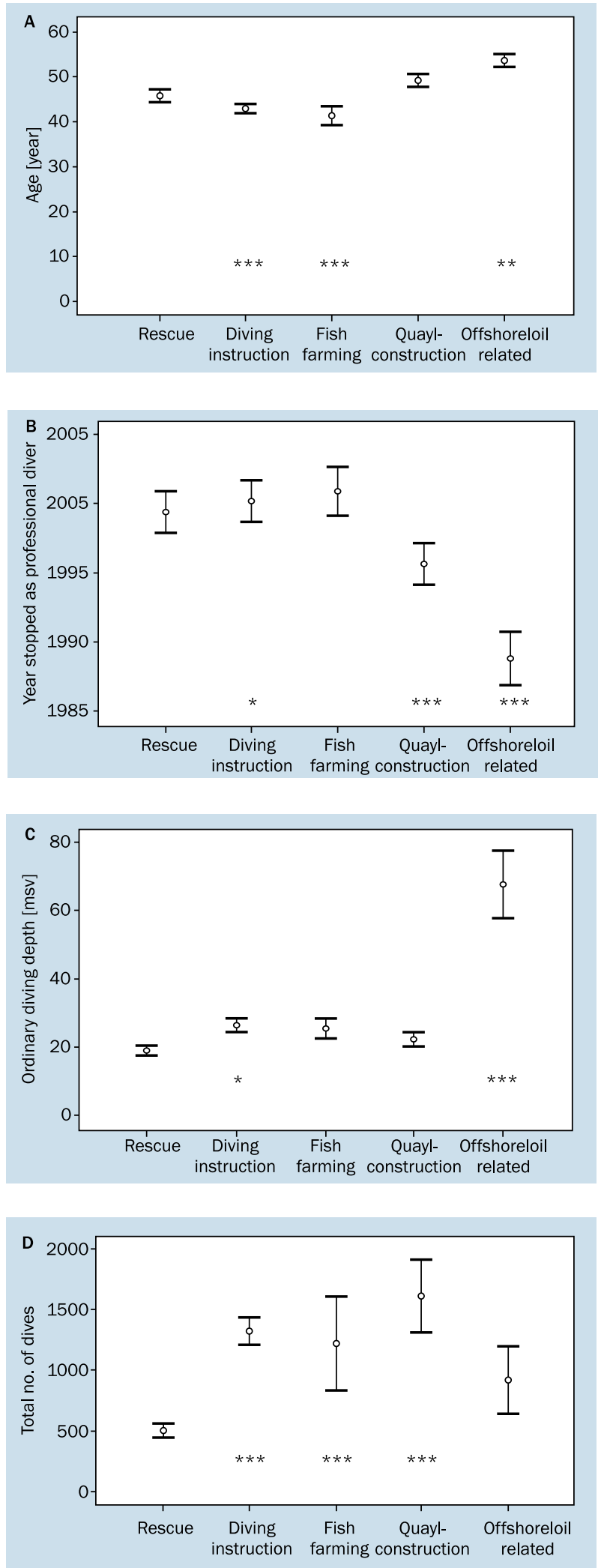

Figure 2. Mean age (A), mean year stopped diving (B), mean ordinary diving depth (C) and mean number of dives (D) among divers in different areas. Corresponding 95\% confidence intervals are shown for each data point. Data retrieved from the "Norwegian diver 2011" project. Compared to rescue divers: $* p<0.05,{ }^{* *} p<0.01,{ }^{* *} p<0.001$ after adjustment for age and total number of dives where this can be done 
Table 2. Number of divers reporting heavy workload, physically demanding diving and demanding events due to diving. Data retrieved from the "Norwegian diver 2011" project

\begin{tabular}{|c|c|c|c|c|c|}
\hline & No. of divers (\%) & Crude RR & $95 \% \mathrm{CI}$ & Adjusted RR* & $95 \% \mathrm{CI}$ \\
\hline \multicolumn{6}{|l|}{ Physically demanding diving } \\
\hline Rescue & $18(5.7)$ & 1 & & 1 & \\
\hline Diving instruction & $40(10.7)$ & 1.87 & $1.09-3.19$ & 1.51 & $0.83-2.75$ \\
\hline Fish farming & $24(21.4)$ & 3.74 & $2.11-6.62$ & 2.88 & $1.45-5.73$ \\
\hline Quay/construction & $72(24.6)$ & 4.29 & $2.62-7.01$ & 3.71 & $2.09-6.57$ \\
\hline Offshore/oil related & $18(24.3)$ & 4.24 & $2.32-7.75$ & 4.78 & $2.30-9.93$ \\
\hline \multicolumn{6}{|c|}{ No day off after 3 days of physically demanding diving } \\
\hline Rescue & $26(8.3)$ & 1 & & 1 & \\
\hline Diving instruction & $29(7.8)$ & 0.94 & $0.56-1.56$ & 0.89 & $0.50-1.59$ \\
\hline Fish farming & $24(21.4)$ & 2.59 & $1.55-4.32$ & 2.56 & $1.35-4.85$ \\
\hline Quay/construction & $44(15.0)$ & 1.81 & $1.15-2.87$ & 1.63 & $0.94-2.85$ \\
\hline Offshore/oil related & $13(17.6)$ & 2.12 & $1.15-3.93$ & 1.99 & $0.95-4.20$ \\
\hline \multicolumn{6}{|c|}{ Repeated dives after one physically demanding dive } \\
\hline Rescue & $4(1.3)$ & 1 & & 1 & \\
\hline Diving instruction & $19(5.1)$ & 3.99 & $1.37-11.6$ & 3.14 & $1.05-9.38$ \\
\hline Fish farming & $17(15.2)$ & 11.9 & $4.10-34.7$ & 8.43 & $2.68-26.5$ \\
\hline Quay/construction & $27(9.2)$ & 7.23 & $2.56-20.4$ & 5.21 & $1.75-15.5$ \\
\hline Offshore/oil related & $4(5.4)$ & 4.24 & $1.09-16.6$ & 3.92 & $0.94-16.3$ \\
\hline \multicolumn{6}{|l|}{ Life threatening events } \\
\hline Rescue & $199(63.4)$ & 1 & & 1 & \\
\hline Diving instruction & $257(68.7)$ & 1.08 & $0.85-1.38$ & 1.04 & $0.81-1.34$ \\
\hline Fish farming & $89(79.5)$ & 1.25 & $0.90-1.74$ & 1.21 & $0.86-1.72$ \\
\hline Quay/construction & 243 (82.9) & 1.31 & $1.02-1.67$ & 1.26 & $0.97-1.64$ \\
\hline Offshore/oil related & $65(87.8)$ & 1.39 & 095-2.02 & 1.39 & $0.94-2.07$ \\
\hline \multicolumn{6}{|l|}{ Psychologically demanding events } \\
\hline Rescue & 293 (93.3) & 1 & & 1 & \\
\hline Diving instruction & $237(63.4)$ & 0.68 & $0.54-0.85$ & 0.62 & $0.49-0.79$ \\
\hline Fish farming & $64(57.1)$ & 0.61 & $0.43-0.87$ & 0.56 & $0.39-0.81$ \\
\hline Quay/construction & $201(68.6)$ & 0.74 & $0.58-0.94$ & 0.66 & $0.50-0.85$ \\
\hline Offshore/oil related & $55(74.3)$ & 0.93 & $0.80-1.09$ & 0.76 & $0.51-1.14$ \\
\hline
\end{tabular}

*Adjusted for age and total number of dives; $\mathrm{Cl}$ - confidence interval; $\mathrm{RR}$ - relative risk

A total of 1149 (99\%) responded to the question "Have you ever been unconscious during diving". Among these 55 (4.8\%) had experienced unconsciousness. The divers in quay/construction and offshore/oil related diving had a higher relative risk of unconsciousness compared to rescue divers (Table 3).

\section{SUBJECTIVE HEALTH PROBLEMS}

A total of 205 (17.6\%) divers reported that diving had affected their health in a negative way; this proportion differed between study groups (Table 3 ). The divers in quay/construc- tion and offshore/oil related diving more often reported an adverse effect compared to rescue divers (Table 3).

The divers in fish farming, quay/construction and offshore/oil related diving obtained a higher symptom score compared to rescue divers (Fig. 3A).

Diving instructors, divers in fish farming, quay/construction and offshore/oil related divers had a significantly poorer health related quality of life (HRQL) than rescue divers; for both physical component summary (PCS) (Fig. 3B) and mental component summary (MSC) (Fig. 3C). 
Table 3. Number of divers reporting adverse health outcomes due to diving. Data retrieved from the "Norwegian diver 2011" project

\begin{tabular}{|c|c|c|c|c|c|}
\hline Objective & No. of divers (\%) & Crude RR & $95 \% \mathrm{Cl}$ & Adjusted RR* & $95 \% \mathrm{Cl}$ \\
\hline \multicolumn{6}{|l|}{ Decompression sickness } \\
\hline Rescue & $19(6.2)$ & 1 & & 1 & \\
\hline Diving instruction & $61(16.5)$ & 2.67 & $1.63-4.37$ & 2.56 & $1.46-4.51$ \\
\hline Fish farming & $20(18.2)$ & 2.94 & $1.63-5.29$ & 2.90 & $1.44-5.86$ \\
\hline Quay/construction & $64(22.4)$ & 3.62 & $2.22-5.88$ & 2.96 & $1.65-5.29$ \\
\hline Offshore/oil related & $26(36.1)$ & 5.84 & $3.42-9.94$ & 5.28 & $2.66-10.5$ \\
\hline \multicolumn{6}{|l|}{ Unconsciousness } \\
\hline Rescue & $5(1.6)$ & 1 & & 1 & \\
\hline Diving instruction & $10(2.7)$ & 1.65 & $0.57-4.79$ & 1.48 & $0.50-4.39$ \\
\hline Fish farming & $1(0.9)$ & 0.55 & $0.07-4.67$ & 0.54 & $0.06-4.75$ \\
\hline Quay/construction & $24(8.3)$ & 5.10 & $1.97-13.2$ & 3.80 & $1.39-10.4$ \\
\hline Offshore/oil related & $15(20.3)$ & 12.4 & $4.66-33.0$ & 8.10 & $2.72-24.1$ \\
\hline \multicolumn{6}{|l|}{ Adverse effect of diving } \\
\hline Total & $205(17.6)$ & & & & \\
\hline Rescue & $33(10.5)$ & 1 & & 1 & \\
\hline Diving instruction & $36(9.6)$ & 0.92 & $0.59-1.43$ & 0.70 & $0.41-1.17$ \\
\hline Fish farming & $24(21.4)$ & 2.04 & $1.26-3.29$ & 1.79 & $0.99-3.24$ \\
\hline Quay/construction & $76(25.0)$ & 2.47 & $1.69-3.60$ & 1.94 & $1.21-3.09$ \\
\hline Offshore/oil related & $36(48.6)$ & 4.63 & $3.11-6.90$ & 3.95 & $2.24-6.97$ \\
\hline
\end{tabular}

*Adjusted for age and total number of dives; $\mathrm{Cl}$ - confidence interval; $\mathrm{RR}$ - relative risk

\section{DISCUSSION}

Compared to the rescue divers, divers in quay/construction work and offshore/oil related divers reported more adverse health effects and obtained a higher symptom score. Large differences were observed between the various groups of professional divers. For most diving related health problems, diving instructors and rescue divers were less affected than divers in fish farming, quay/construction work and offshore/oil related diving. For several outcomes we observed an increasing frequency from rescue, instructors, fish farming, and quay/construction work up to offshore divers.

Decompression may cause gas bubbles in the circulatory system that result in DCS, and this may manifest itself as skin and joint pain, or as acute neurological symptoms. Permanent health problems have been observed in $20-30 \%$ of cases with neurological DCS [8]. In studies of professional divers, the effects of cumulative diving exposure and decompression sickness have been observed on lung function and on the central nervous system [9-15]. In addition, diving is associated with dysbaric osteonecrosis and hearing impairment [16-18] and exposure to life threatening events may cause serious psychological distress $[19,20]$.

To our knowledge no other studies have compared occupational health effects in different areas of professional diving.
The group of professional divers was previously identified by the Norwegian authorities for other purposes. Consequently, selection bias was reduced. Still, the main limitation of the study was the low response rate that may have induced a selection bias [21, 22]. We expected that offshore divers were older and that they stopped diving at an earlier stage since the recruitment in this area has been limited in recent years. More unexpected was that quay/ /construction divers stopped so early, since there is ongoing recruitment for this work.

Several of the questions used in the questionnaire were collected from internationally acknowledged instruments, but the diver specific questions were constructed for the present questionnaire and had not been validated.

During the period 1987-1989, a Norwegian offshore diving contractor experienced a considerable increase in DCS [23]. Later the reported incidences of DCS have been very low as indicated in the database DSYS 2014 from the Petroleum Safety Authority Norway, showing only four incidences of DCS in offshore diving on the Norwegian Shelf since 1991, the last one in 2002 [24].

In our study the prevalence of DCS differs between the different types of diving with offshore/oil related diving as the highest. A follow-up study of non-saturation divers in Norway in 2015 reported a prevalence of decompression 

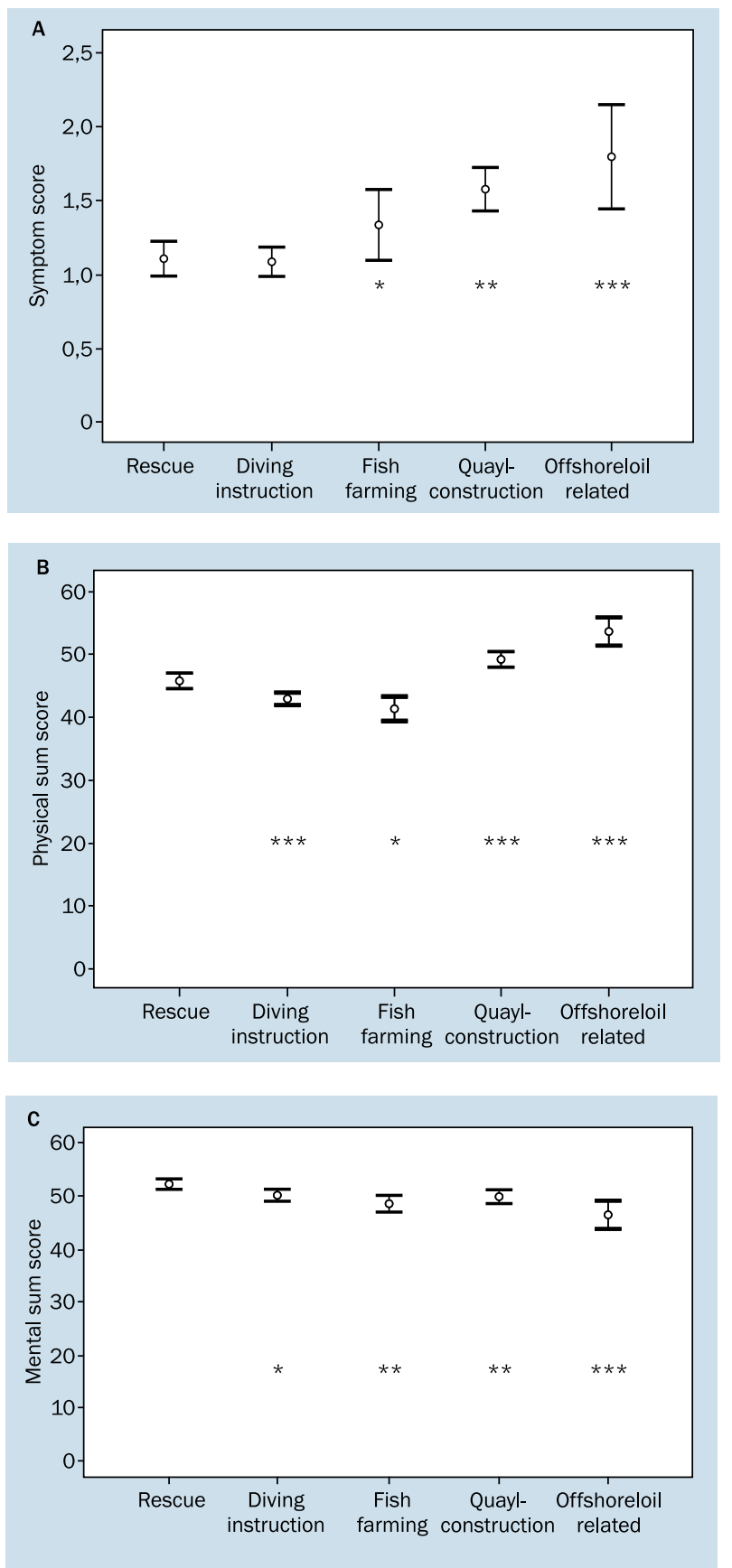

Figure 3. Adverse health symptom score (A), and health related quality of life (SF-12) expressed as physical sum score (B) and mental sum score $(\mathbf{C})$ among divers in different groups. Mean and corresponding $95 \%$ confidence intervals are shown for each branch. Data retrieved from the "Norwegian diver 2011" project. Compared to rescue divers: $* p<0.05, * * p<0.01, * * * p \leq 0.001$ after adjustment for age and total number of dives

illness of $27 \%$ [25]. Of the offshore/oil related divers, $88 \%$ had left the diving industry about 1989 (mean year). In the other groups only $46-67 \%$ of divers had left the industry between 1996 and 2001. Possibly hazardous diving was more frequent prior to 1990 , indicated by the higher prev- alence of DCS. This might be supported by a high risk of reported unconsciousness among North Sea divers, employed before 1990 (58 of 219) [26]. In our study the prevalence of unconsciousness among offshore/oil related divers was $20 \%$, as compared to $0.9-8.3 \%$ in the other study groups.

It should also be noted that rescue divers is the group of divers that had the highest frequency of divers experiencing psychologically demanding events (93.3\%), and yet they reported less adverse health symptoms, and a higher physical and mental score than other groups of divers. This finding may be due to the fact that rescue divers expect to experience such events and that they are taken care of and have a good debriefing system. It is known that prevention of work-related post-traumatic stress disorder includes a sound organisational and psychosocial work environment, systematic training of employees, social support from colleagues and managers and a proper follow-up of employees after a critical event $[27,28]$.

\section{CONCLUSIONS}

Our data demonstrate that dive characteristics such as work load, both physical and mental, vary between different groups of professional divers. Health risks vary between groups of divers, and divers in quay/construction work and offshore/oil related divers have a higher frequency of adverse health effects compared to rescue divers.

Beyond that it is difficult to establish any link between health risks and dive exposure due to the lack of quantitative exposure data. Nevertheless, the data does suggest that in some areas of professional diving there seems to be an increased health risk compared to rescue divers. Further initiatives should be taken to identify the risk factors in order to further reduce unhealthy dive exposure and risk.

\section{ACKNOWLEDGEMENTS}

We would like to thank The Norwegian Labour Inspection Authority who allowed us to use the Diver registry for research purpose and the staff at the Diving School, Bergen University College for practical assistance, Berit Johannessen at the Department of Occupational Medicine for all of her support in the comprehensive task to acquire the correct national identification numbers of the divers.

We also thank the Norwegian Labour Inspection Authority and the Norwegian Centre of Diving Medicine who funded the questionnaire study the "Norwegian diver 2011".

We also thank MD Suzanne Louise Stannard for help with the English language.

\section{SUPPORTERS}

Norwegian centre of diving medicine and The Norwegian Labour Inspection Authority (stamps for the questionnaire study). 


\section{REFERENCES}

1. Regulations regarding health requirements for offshore divers in Norway. The county governor in Rogaland. Available from: http://www.fylkesmannen.no/Documents/Dokument\%20FMRO/ Helse\%20og\%20sosial/Regelverk\%20og\%20styringsdokument/ Helsekravforskriften\%20engelsk\%202011.pdf (March 2016, date last accessed).

2. Irgens Å, Troland K, Thorsen E, Grønning M. Mortality among professional divers in Norway. Occup Med (Lond) 2013; 63: 537-543. doi: $10.1093 /$ occmed/kqt112.

3. Irgens $\AA$, Grønning M. Cancer risk among professional inshore divers in Norway. Int Marit Health 2013; 64: 202-206.

4. Irgens Å, Grønning M, Irgens LM. Pregnancy outcome in partners of male professional divers in Norway. Occup Med (Lond) 2016; Jul 13. pii: kqw087 [Epub ahead of print].

5. Irgens Å, Troland K, Grønning M. Norwegian diver 2011: female professional divers - who are they and what do they do? Caisson 2014; 3: 51 (Abstract EUBS 2014).

6. Dykkerstudien 2011 [The Norwegian diver 2011]. Bergen. Available from: http://www.helse-bergen.no/no/OmOss/Avdelinger/hyperbardykkemedisin/Documents/Dykkerstudien2011.pdf (March 2016, date last accessed).

7. IBM Corp. Released 2011. IBM SPSS Statistics for Windows, Version 22.0. Armonk, NY: IBM Corp.

8. Doolette DJ, Gorman DF. Evaluation of decompression safety in an occupational diving group using self-reported diving exposure and health status. Occup Environ Med 2003; 60: 418-422.

9. Todnem K, Nyland H, Kambestad BK, Aarli JA. Influence of occupational diving upon the nervous-system: an epidemiologic-study. Br J Ind Med 1990; 47: 708-714.

10. Todnem K, Nyland $\mathrm{H}$, Skeidsvoll $\mathrm{H}$ et al. Neurological long-term consequences of deep diving. Br J Ind Med 1991; 48: 258-266.

11. Thorsen $E$, Segadal K, Kambestad B, Gulsvik A. Divers lung-function: small airways disease? Br J Ind Med 1990; 47: 519-523.

12. Thorsen $E$, Segadal K, Kambestad BK. Mechanisms of reduced pulmonary-function after a saturation dive. Eur Respir J 1994; 7: 4-10.

13. Thorsen E, Segadal K, Reed JW, Elliott C, Gulsvik A, Hjelle JO. Contribution of hyperoxia to reduced pulmonary-function after deep saturation dives. J Appl Physiol 1993; 75: 657-662.

14. Vaernes RJ, Klove H, Ellertsen B. Neuropsychologic effects of saturation diving. Undersea Biomed Res 1989; 16: 233-251.

15. Vaernes RJ, Eidsvik S. Central nervous dysfunctions after near-miss accidents in diving. Aviat Space Environ Med 1982; 53: 803-807.

16. Molvaer Ol, Lehmann EH. Hearing acuity in professional divers. Undersea Biomed Res 1985; 12: 333-349.
17. Jiang CQ, Wang B, Yu CF et al. Dysbaric osteonecrosis by X-ray and CT scan in Chinese divers. Undersea Hyperb Med 2005; 32: 169-174.

18. Uzun G, Toklu AS, Yildiz S et al. Dysbaric osteonecrosis screening in Turkish Navy divers. Aviat Space Environ Med 2008; 79: 44-46.

19. Troland K, Sundal E, Irgens A, Gronning M, Thorsen E. Potentially traumatic events and posttraumatic stress reaction in retired North Sea divers. Proceedings of the XXVIIth annual meeting of the European Underwater Biomedical Society (EUBS). Gdansk, Poland: EUBS, 2011: 22. Available from: http://www.daneurope. org/c/document_library/get_file?uuid=c57ead31-16fe-4d8f -88bc-a302540ef22b\&groupld=10103 (March 2016, date last accessed).

20. Pionerdykkerne i Nordsjøen [The pioneer divers in the North Sea]. Oslo: Ministry of Government Administration, Reform and Church Affairs, NOU 2003:5 [Commission of Enquiry to investigate all circumstances related to diving in the North Sea in the pioneer period.]. Available from: https://www.regjeringen.no/nb/dokumenter/nou2003-5/id381525/ (March 2016, date last accessed).

21. Myrtveit SM, Ariansen AM, Wilhelmsen I, Krokstad S, Mykletun A. A population based validation study of self-reported pensions and benefits: the Nord-Trøndelag health study (HUNT). BMC Res Notes 2013; 6: 27. doi: 10.1186/1756-0500-6-27.

22. Bjertnaes OA, Garratt A, Botten G. Nonresponse bias and cost-effectiveness in a Norwegian survey of family physicians. Eval Health Prof 2008; 1: 65-80. doi: 10.1177/0163278707311874.

23. Jacobsen G, Jacobsen JE, Peterson RE et al. Decompression sickness from saturation diving: a case control study of some diving exposure characteristics. Undersea Hyperb Med 1997; 2: 73-80.

24. Incidents in connection with diving. Petroleum Safety Authority Norway's (PSA's) report from the DSYS diving database. 2015. Available from: http://www.psa.no/news/report-incidents-in-connection -with-diving-article9222-878.html (June 2016, date last accessed).

25. Bast-Pettersen R, Skare $\varnothing$, Nordby KC, Skogstad M. A twelve-year longitudinal study of neuropsychological function in non-saturation professional divers. Int Arch Occup Environ Health 2015; 88: 669-682. doi: 10.1007/s00420-014-0991-0.

26. Sundal E, Irgens Å, Troland K, Thorsen E, Grønning M. Prevalence and causes of loss of consciousness in former North Sea occupational divers. Int Marit Health 2013; 3: 142-147.

27. Leffler CT, Dembert ML. Posttraumatic stress symptoms among U.S. navy divers recovering TWA flight 800. J Nerv Ment Dis 1998; 186: 574-577.

28. Skogstad, M, Skorstad M, Lie A, Conradi HS, Heir T, Weisæth L. Work-related post-traumatic stress disorder. Occup Med (Lond) 2013; 63: 175-182. doi: 10.1093/occmed/kqt003. 